\title{
Biopsy-proven adenoviral diarrhea responding to low-dose cidofovir
}

\author{
N.P. Nicolasora, P. Reddy, D.R. Kaul. Biopsy-proven adenoviral diarrhea \\ responding to low-dose cidofovir. \\ Transpl Infect Dis 2008: 10: 346-350. All rights reserved
}

\begin{abstract}
We present a case of diarrhea secondary to biopsy-proven adenovirus (ADV) infection after autologous peripheral hematopoietic stem cell transplant for multiple myeloma. The patient had a negative plasma polymerase chain reaction for ADVand a dramatic clinical response to low-dose cidofovir. To our knowledge, this is the first report in an adult hematopoietic stem cell recipient of the use of low-dose cidofovir to treat proven ADV gastrointestinal infection.
\end{abstract}

\author{
N.P. Nicolasora', P. Reddy ${ }^{\mathbf{2}}$, D.R. Kaul ${ }^{1}$ \\ ${ }^{1}$ Department of Medicine, Division of Infectious Diseases and \\ ${ }^{2}$ Blood and Bone Marrow Transplant Program, Department of \\ Internal Medicine, Division of Hematology-Oncology, \\ University of Michigan Medical School, Ann Arbor, Michigan, \\ USA
}

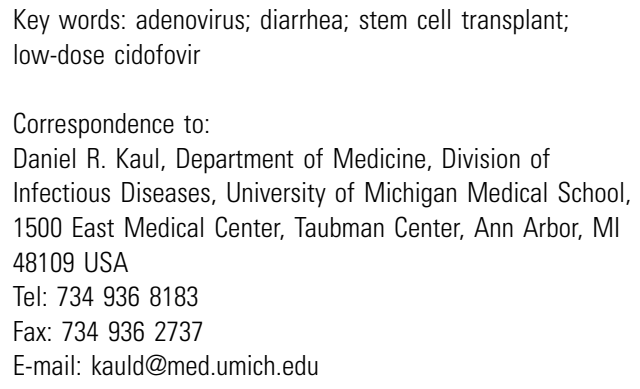

Adenovirus (ADV) is a common cause of self-limited upper respiratory, conjunctival, or gastrointestinal (GI) disease in immunocompetent individuals, but has emerged as a pathogen causing significant morbidity in transplant patients. In hematopoietic stem cell transplant (HSCT) recipients, the incidence of $\mathrm{ADV}$ infection has been reported to be anywhere between $3 \%$ and $47 \%(1-15)$. Asymptomatic infection due to ADV manifests as GI or urinary shedding and usually precedes symptomatic disease $(13,16,17)$. Both urinary and GI tracts are the commonly observed sites of adenoviral disease in HSCT recipients (5-7, 9-13). Current standard treatment for systemic ADV disease, based on small studies, is high-dose cidofovir ( $5 \mathrm{mg} / \mathrm{kg} \mathrm{q} 1-2$ weeks) with probenicid (17-22). Low-dose cidofovir (LDC) (i.e., $1 \mathrm{mg} / \mathrm{kg} 3$ times a week) has been tried for ADV-associated hemorrhagic cystitis and non-urinary tract disease in children $(9,23,24)$, and disseminated disease and hemorrhagic cystitis in adult allogeneic HSCT recipients (15). However, the efficacy of LDC therapy for ADV-associated GI disease following HSCT is not known. Because of the nephrotoxicity of cidofovir, LDC may be an attractive option for some patients. We report a case of diarrhea due to ADVafter autol- ogous HSCT that responded well to LDC. The patient had a negative plasma polymerase chain reaction (PCR) for $\mathrm{ADV}$ but had proven ADV-induced diarrhea based on clinical presentation and positive GI tract biopsy.

\section{Case presentation}

A 66 -year-old male was diagnosed in 1/06 with stage IIIA immune globulin $\mathrm{G}$ ( $\operatorname{IgG}$ ) $\kappa$-multiple myeloma. His disease was initially diagnosed following a chest computed tomography (CT) scan that was done for evaluation of chest pain, and revealed a left chest wall mass that on biopsy was a plasmacytoma. Subsequently, he had a bone marrow biopsy, which showed $51 \%$ plasma cells consistent with multiple myeloma. He received approximately a year of dexamethasone and thalidomide and was in near complete remission before his transplant. He had low-level persistence of myeloma cells in his bone marrow 2 weeks before his transplant. His serum calcium (peak $11 \mathrm{mg} / \mathrm{dL}$; normal 
value [NV]: $8.6-10.3 \mathrm{mg} / \mathrm{dL}$ ) and $\mathrm{IgG}$ protein (peak: $6 \mathrm{~g} / \mathrm{dL}$; NV: $0.56-1.25 \mathrm{~g} / \mathrm{dL}$ ) had normalized. His $\beta-2$ microglobulin remained elevated at $2.2-3.0 \mathrm{mg} / \mathrm{dL}$ (NV: $0-2 \mathrm{mg} / \mathrm{dL}$ ). Before he developed multiple myeloma, the patient also had a history of well-controlled atrial fibrillation, hypothyroidism, and depression.

The patient received melphalan $\left(200 \mathrm{mg} / \mathrm{m}^{2}\right) 2$ days before transplant. He was infused with the following autologous stem cell doses: $2.3 \times 10^{6}$ and $0.86 \times 10^{6} \mathrm{CD} 34+$ cells $/ \mathrm{kg}$ on days 1 and 2, respectively. Post transplant, he was given low-dose dexamethasone at $4 \mathrm{mg}$ b.i.d. for 4 days. Two days after HSCT, he had intractable nausea and vomiting, resulting in dehydration and multiple electrolyte deficiencies that required him to be on total parenteral nutrition. He also developed a rapid ventricular response from his atrial fibrillation, which was controlled with metoprolol and digoxin. He received cefepime after he developed a low-grade fever. This was discontinued 4 days later after chest radiograph, blood, and urine cultures were negative. His nadir absolute neutrophil count of 600 cells $/ \mathrm{mm}^{3}$ lasted only for a day, with most values above 1000 cells/ $\mathrm{mm}^{3}$. Five days post transplant, he developed large volume (maximum $\sim 4-6 \mathrm{~L} /$ day), watery diarrhea with a peak frequency of 15-20 bowel movements/day. He did not respond to octreotide or loperamide. The following studies were negative: stool bacterial culture, stool examination for ova and parasites, stool rotavirus antigen by enzyme immunoassay (EIA), shiga-like toxin assay by EIA, human herpesvirus 6 and cytomegalovirus (CMV) plasma PCR, and Clostridium difficile $\mathrm{A}$ and $\mathrm{B}$ toxin assay $(\times 3)$. His absolute lymphocyte count (ALC) remained $<400$ cells $/ \mathrm{mm}^{3}$ for at least 2 weeks while he was having diarrhea (Fig. 1). He had a positive stool ADV antigen by EIA on day 6 of illness. His ADV serum antibody was negative. Stool examination for white blood cells, stool viral culture, and ADV serotyping were not performed. His plasma ADV PCR was checked twice and was negative. He had a CTscan of his abdomen and pelvis on day 7 of his diarrhea, which showed diffuse small bowel thickening (Fig. 2). A colonoscopy and esophagogastroduodenoscopy on day 10 of his illness showed the following: esophagitis (distal third); diffuse, moderate mucosal abnormality characterized by congestion and decreased vascular pattern in the stomach; moderate hemorrhagic appearance in the cardia; diffuse nodular mucosa in the duodenum; and congestion, granular, and vascular-pattern-decreased mucosa in his rectosigmoid and descending colon. The infectious disease division was consulted on day 10 and LDC ( $1 \mathrm{mg} / \mathrm{kg} 3$ times a week) was started. Probenecid was not given because the patient could not tolerate anything by mouth. Adequate intravenous hydration was ensured. Renal function remained stable (baseline creatinine was $0.8 \mathrm{mg} / \mathrm{dL}$, and after LDC creatinine was $0.6 \mathrm{mg} / \mathrm{dL}$ [NV: $0.7-1.3 \mathrm{mg} / \mathrm{dL}]$ ). Two days after starting LDC, the volume of his diarrhea improved dramatically and resolved completely within 2 weeks of treatment (Fig. 1). Biopsy of his stomach (Fig. 3), duodenum, and colon revealed ADV inclusions. Immunohistochemical staining for ADV from all biopsied sites was also positive (Fig. 4). The patient was CMV IgG negative but herpes simplex virus (HSV) IgG positive, thus immunohistochemical staining for the latter virus was also done on these tissue samples and found to be negative.

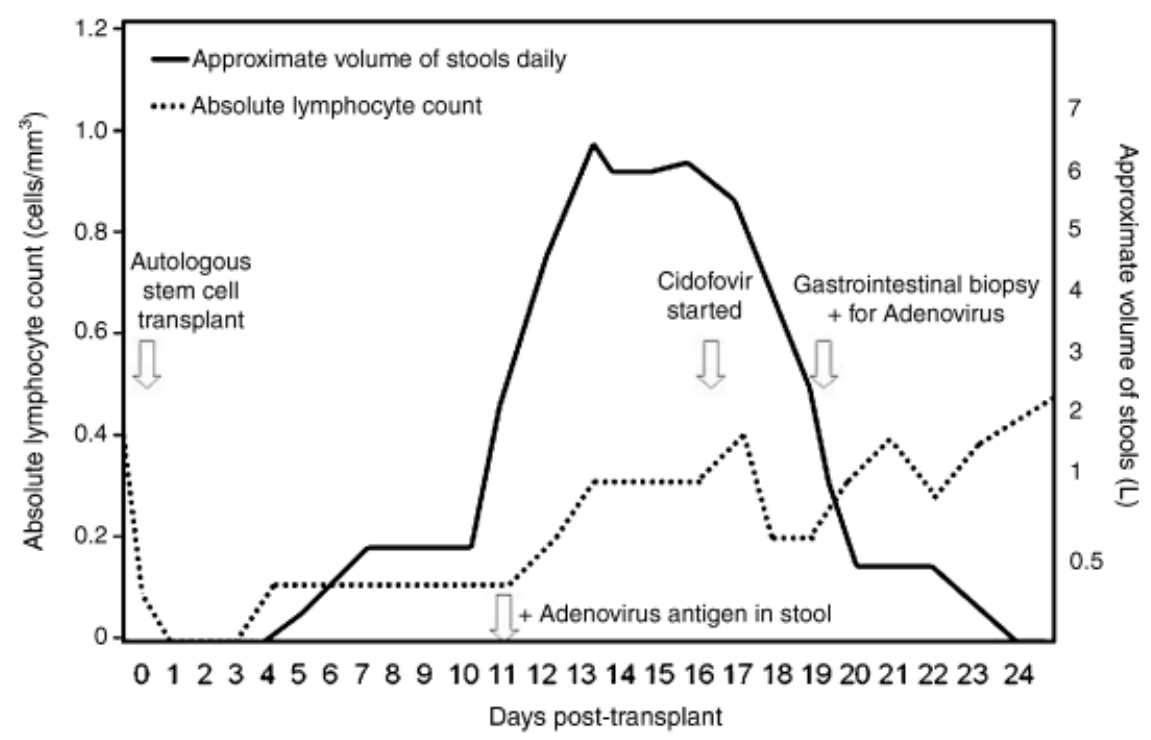

Fig. 1. Diagram showing a summary of clinical events. 


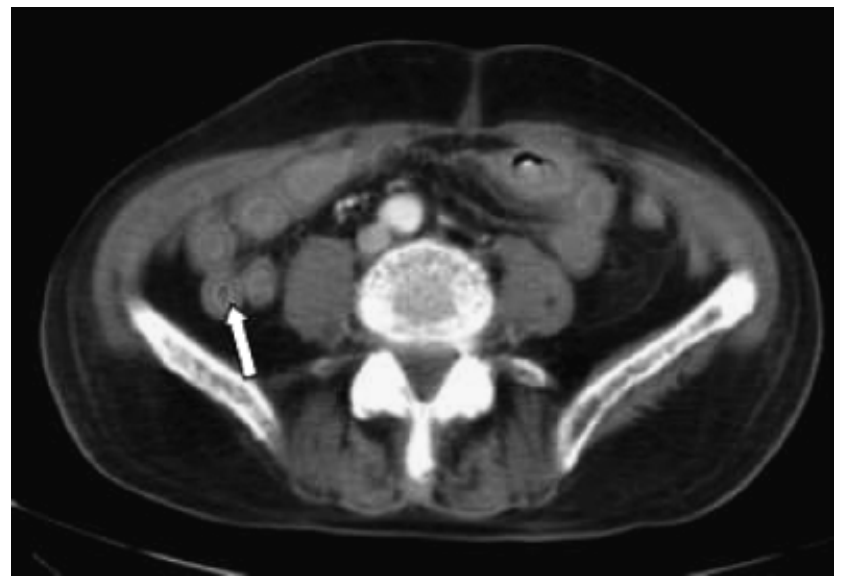

Fig. 2. Computed tomography scan of the abdomen showing diffuse small bowel thickening (white arrow points to a 'ring' outlining the bowel lumen, which signifies mucosal enhancement).

\section{Discussion}

In this report, we describe a case of ADV infection of the GI tract that responded dramatically to LDC. The case was diagnosed based on clinical presentation, stool ADV antigen, and confirmed by biopsy. The report also emphasizes that significant GI tract disease may be present with a

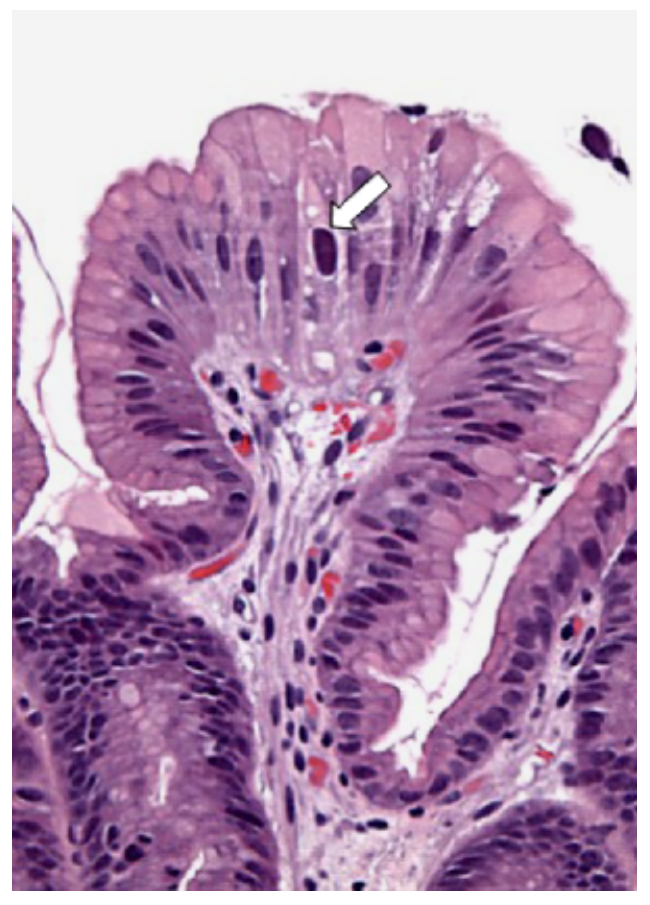

Fig. 3. Hematoxylin and eosin stain of gastric rugae with typical adenovirus inclusions called 'smudge cells' (white arrow).

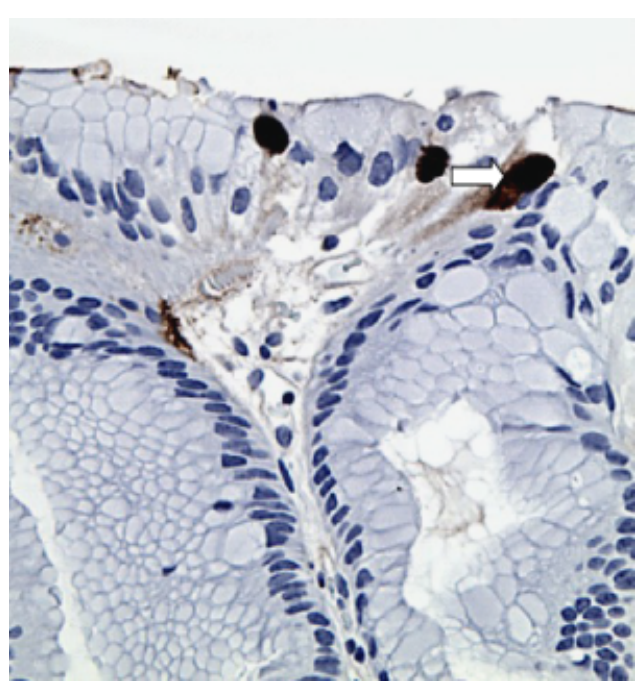

Fig. 4. Immunohistochemical stain of gastric mucosal biopsy positive for adenovirus (white arrow).

negative plasma PCR even in highly immunosuppressed hosts.

In HSCT recipients, ADV is commonly associated with upper and/or lower respiratory tract infection, GI disease, hepatitis, or hemorrhagic cystitis (25). Diarrhea caused by ADV may be difficult to distinguish from other causes of diarrhea such as Clostridium difficile infection, CMV colitis, chemotherapy, and graft-versus-host disease (GVHD) (26, 27). In its most severe form, patients can develop hemorrhagic colitis. The serotypes most commonly detected in transplant recipients with diarrhea belong to subgroups B and $\mathrm{C}$; these subgroups also account for the majority of clinical isolates in HSCT patients worldwide $(1,2,26)$.

ADV disease in HSCT recipients is usually a reactivation of latent infection and is more common in children, patients with T-cell depleted or mismatched grafts, and patients with acute GVHD (25). ADV disease is less common in recipients of autologous transplants than allogeneic transplants $(2-12 \%$ in autografts vs. $12-18 \%$ in matched sibling transplant, and $16-30 \%$ in mismatched related and unrelated transplants) (28).

Distinguishing ADV disease from asymptomatic GI tract infection can be difficult. Viral shedding without clinical disease from the inactive or latent state of the virus in the GI tract is common $(13,16,17)$. Thus, in questionable cases the decision to start a nephrotoxic and expensive drug (i.e., cidofovir) is difficult (25). In our case, a positive direct immunohistochemical stain for ADV and the presence of typical nuclear inclusions (i.e., smudge cells) from GI tract biopsies (both stomach and colon) in the setting of a compatible clinical presentation (i.e., diarrhea), provided a definite diagnosis of ADV disease. Our case re-emphasizes 
the fact that definite GI tract disease may not be accompanied by viremia, and that a negative plasma PCR result does not rule out invasive GI tract disease $(13,29)$. In our case, we proceeded with empiric treatment with LDC before the biopsy results, because of the compatible clinical picture and lack of alternative diagnosis. We chose LDC over standard-dose cidofovir based on the theoretical advantage of decreased risk for nephrotoxicity in this patient who did not have evidence of disseminated disease. Caveats to the use of LDC are reports of breakthrough infection with certain herpesviruses (HSV and CMV) (24) and the need to continue appropriate prophylaxis.

Two case series describe the use of LDC for ADV infection (other than hemorrhagic cystitis) in HSCT recipients $(9,15)$. In the first report, 8 pediatric recipients of allogeneic HSCT were treated with at least 9 doses of LDC. Duration of treatment ranged from 3 weeks to 8 months, and only 1 patient had a significant increase in serum creatinine. Six of the 8 patients were reported to be alive and culture negative (9). In the second report, 3 allogeneic HSCT recipients received initial therapy with at least 2 doses of LDC every other day for disseminated disease and all died of disseminated disease (15). Other reports of LDC for the treatment of ADV-associated hemorrhagic cystitis have been published $(15,23,24)$ but, because of the ability of the drug to achieve a high concentration in the urine, these reports may not be relevant to disease outside the urinary tract. To our knowledge, this is the first report to describe the use of LDC in an adult HSCT recipient with proven, localized ADV disease outside of the urinary tract.

Evaluation of response to antiviral agents and recovery from ADV disease is limited because most of the data are retrospective in nature (25). In our report, treatment with LDC was temporally associated with clinical recovery from diarrhea. However,T-cell immunity is critical for protection against ADV infection, reactivation, and recovery (11, 30, 31). The concept of T-cell defense against ADV infection underlies attempts to treat ADV disease with donor lymphocyte infusion or targeted adoptive immunotherapy using the patient's own ADV-specific antibodies $(30,32)$. Therefore, the clinical response in our patient may also be accounted for by spontaneous recovery $(11,29)$, or recovery of T-cell function independent of cidofovir effect. Our patient had a low ALC $\left(<400\right.$ cells $\left./ \mathrm{mm}^{3}\right)$ when he became symptomatic from ADV infection. He had a slow but sustainable rise in ALC that coincided with improvement of diarrhea following administration of cidofovir.

This case report, together with other small published data, suggests that use of LDC for the treatment of ADV disease might be an efficacious strategy (9). It should be noted that 1 case series demonstrated poor outcomes with LDC in patients with disseminated disease (15). LDC may possibly be tried in the following situations: preemptive therapy to prevent disseminated disease, in mild and localized forms of the disease (i.e., non-disseminated), and possibly in patients with ADV disease and renal dysfunction. Determining the appropriate role of LDC in the treatment of adenoviral disease in this population will, however, require prospective clinical trials.

\section{References}

1. Shields AF, Hackman RC, Fife KH, et al. Adenovirus infections in patients undergoing bone marrow transplantation. N Engl J Med 1985; 312: 529-533.

2. Flomenberg P, Babbitt J, Drobyski WR, et al. Increasing incidence of adenovirus disease in bone marrow transplant recipients. J Infect Dis 1994; 169: 775-781.

3. Blanke C, Clark C, Broun R, et al. Evolving pathogens in allogeneic bone marrow transplantation: increased fatal adenoviral infections. Am J Med 1995; 99: 326-368.

4. Munoz FM, Piedra PA, Demmler GJ. Disseminated adenovirus disease in immunocompromised and immunocompetent children. Clin Infect Dis 1998; 27: 1194-1200.

5. Hale GA, Heslop HE, Krance RA, et al. Adenovirus infection after pediatric bone marrow transplantation. Bone Marrow Transplant 1999; 23: 277-282.

6. Howard DS, Phillips GL, Reece DE, et al. Adenovirus infections in hematopoietic stem cell transplant recipients. Clin Infect Dis 1999; 29: 1494-1501.

7. Baldwin A, Kingman H, Darville M, et al. Outcome and clinical course of 100 patients with adenovirus infection following bone marrow transplantation. Bone Marrow Transplant 2000; 26: $1333-1338$.

8. Runde V, Ross S, Trenschel R, et al. Adenoviral infection after allogeneic stem cell transplantation: report on 130 patients from a single SCTunit involved in a prospective multicenter surveillance study. Bone Marrow Transplant 2001; 28: 51-57.

9. Hoffman JA, Shah AJ, Ross LA, et al. Adenoviral infections and a prospective trial of cidofovir in pediatric hematopoietic stem cell transplantation. Biol Blood Marrow Transplant 2001; 7: 388-394.

10. La Rosa AM, Champlin RE, Mirza N, et al. Adenovirus infections in adult recipients of blood and marrow transplants. Clin Infect Dis 2001; 32: 871-876.

11. Chakrabarti S, Mautner V, Osman H, et al. Adenovirus infections following allogeneic stem cell transplantation: incidence and outcome in relation to graft manipulation, immunosuppression, and immune recovery. Blood 2002; 100: 1619-1627.

12. Bruno B, Gooley T, Hackman RC, et al. Adenovirus infection in hematopoietic stem cell transplantation: effect of ganciclovir and impact on survival. Biol Blood Marrow Transplant 2003; 9: 341-352.

13. Lion T, Baumgartinger R, Watzinger $\mathrm{F}$, et al. Molecular monitoring of adenovirus in peripheral blood after allogeneic bone marrow transplantation permits early diagnosis of disseminated disease. Blood 2003; 102: 1114-1120.

14. Humar A, Kumar D, Mazzulli T, et al. A surveillance study of adenovirus infection in adult solid-organ transplant recipients. Am J Transplant 2005; 5: 2555-2559.

15. Symeonidis N, Jakubowski A, Pierre-Louis S, et al. Invasive adenoviral infections in T-cell-depleted allogeneic hematopoietic stem cell transplantation: high mortality in the era of cidofovir. Transpl Infect Dis 2007; 9: 108-113. 
16. Walls T, Hawrami K, Ushiro-Lumb I, et al. Adenovirus infection after pediatric bone marrow transplantation: is treatment always necessary? Clin Infect Dis 2005; 40: 1244-1249.

17. Kampmann B, Cubitt D, Walls T, et al. Improved outcome for children with disseminated adenoviral infection following allogeneic stem cell transplantation. Br J Haematol 2005; 130: 595-603.

18. Legrand F, Berrebi D, Houhou N, et al. Early diagnosis of adenovirus infection and treatment with cidofovir after bone marrow transplantation in children. Bone Marrow Transplant 2001; 27: 621-626.

19. Neofytos D, Ojhal A, Mokerjee B, et al. Treatment of adenovirus disease in stem cell transplant recipients with cidofovir. Biol Blood Marrow Transplant 2007; 13: 74-81.

20. Ljungman P, Ribaud P, Eyrich M, et al. Cidofovir for adenovirus infections after allogeneic hematopoietic stem cell transplantation: a survey by the Infectious Diseases Working Party of the European Group for Blood and Marrow Transplantation. Bone Marrow Transplant 2003; 31: 4816.

21. Leruez-Ville M, Minard V, Lacaille F, et al. Real-time blood plasma polymerase chain reaction for management of disseminated adenovirus infection. Clin Infect Dis 2004; 38: 45-52.

22. Muller WJ, Levin MJ, Shin YK, et al. Clinical and in vitro evaluation of cidofovir for treatment of adenovirus infection in pediatric hematopoietic stem cell transplant recipients. Clin Infect Dis 2005; 41: 1812-1816.

23. Hatakeyama N, Suzuki N, Kudoh T, et al. Successful cidofovir treatment of adenovirus-associated hemorrhagic cystitis and renal dysfunction after allogenic bone marrow transplant. Pediatr Infect Dis J 2003; 22: 928-929.
24. Nagafuji K, Aoki K, Henzan H, et al. Cidofovir for treating adenoviral hemorrhagic cystitis in hematopoietic stem cell transplant recipients. Bone Marrow Transplant 2004; 34: 909-914.

25. Ison MG. Adenovirus infections in transplant recipients. Clin Infect Dis 2006; 43: 331-339.

26. Chakrabarti S, Collingham KE, Stevens RH, et al. Isolation of viruses from stools in stem cell recipients: prospective surveillance study. Bone Marrow Transplant 2000; 25: 277-182.

27. Cox GJ, Matsui SM, Lo RS, et al. Etiology and outcome of diarrhea after marrow transplantation: a prospective study. Gastroenterology 1994; 107: 1398-1407.

28. Chakrabarti S, Collingham KE, Fegan CD, et al. Adenovirus infections following haematopoietic cell transplantation: is there a role for adoptive immunotherapy? Bone Marrow Transplant 2000; 26 : 305-307.

29. Avivi I, Chakrabarti S, Milligan DW, et al. Incidence and outcome of adenovirus disease in transplant recipients after reduced-intensity conditioning with alemtuzumab. Biol Blood Marrow Transplant 2004; 10: 186-194.

30. FeuchtingerT, Lucke J, Hamprecht K, et al. Detection of adenovirusspecific Tcells in children with adenovirus infection after allogeneic stem cell transplantation. Br J Haematol 2005; 128: 503-509.

31. Heemskerk B, Lankester AC, van Vreeswijk T, et al. Immune reconstitution and clearance of human adenovirus viremia in pediatric stem-cell recipients. J Infect Dis 2005; 191: 520-530.

32. Hromas R, Cornetta K, Srour E, Blanke C, Broun ER. Donor leukocyte infusion as therapy of life-threatening adenoviral infections after T-cell-depleted bone marrow transplantation. Blood 1994; 84: 1689-1690. 